\title{
Sequential City Growth: Empirical Evidence
}

\author{
David Cuberes*
}

\author{
Clemson University \\ Royal Holloway, University of London
}

This draft: April 2009

\begin{abstract}
Using two comprehensive datasets on population of cities (1800-2000) and metropolitan areas (1960-2000) for a large set of countries, I present three new empirical facts about the evolution of city growth. First, the distribution of cities growth rates is skewed to the right in most countries and decades. Second, within a country, the rank of each decade's fastest growing cities tends to increase over time. Finally, this rank grows faster in periods of rapid growth in urban population. It is argued that these three observations can be rationalized with a simple urban growth model that predicts sequential city growth.
\end{abstract}

\section{Introduction}

This paper explores some new empirical regularities in the process of city growth. Recently, Henderson and Venables (2008) and Cuberes (2008) have developed theoretical models of city formation in which urban agglomerations grow sequentially, with the initially largest ones being the first to grow until they reach a critical size. However, no attempt has been done to test these models.

Using historical data on population of both administratively defined cities and metropolitan areas for a large set of countries I show that the hypothesis of sequential city growth receives strong empirical support. In particular, I first show that in most decades and countries the distribution of cities growth rates is skewed to the right, indicating that a few cities grow much faster than the rest. Second, I study the behavior of the cities that grow the fastest in each decade. The average rank of the $25 \%$ fastest growing cities tends to increase over time, which suggests that the initially largest cities are the first

\footnotetext{
* I would like to thank Antonio Ciccone, Jan Eeckhout, Vernon Henderson, Tom Mroz, Casey Mulligan, Curtis Simon, Robert Tamura, Paul Wilson, and two anonymous referees for very productive comments. Adam Blott provided very able research assistance. Useful suggestions were also received from seminar participants at the University of Chicago, Clemson University, Universidad de Alicante, Bank of Spain, Universidad de Navarra, Universidad del Pais Vasco, Universitat Autonoma de Barcelona, Universitat Pompeu Fabra, the 2005 North American Regional Science Council, the 2006 Summer Econometric Society, and the 2006 Southern Economic Association. All remaining errors are mine. E-mail: cuberes@clemson.edu
} 
ones to grow and that they keep growing faster than the rest until they reach a critical size. Once that happens, the second largest city starts growing, then the third one, and so on. Finally, I show that this process of sequential growth is more pronounced in episodes of fast growth in urban population.

The study of city formation and city growth is important to formulate effective policies in countries whose population is changing rapidly. The novel empirical facts presented in this paper show that the evolution of city population growth exhibits a very consistent time pattern across countries. The specifics of this pattern may have interesting implications for academics and policymakers. Consider, for instance, the analysis of how labor and capital flows will evolve in regions that experience a process of economic and political integration. The most obvious case of such integration is the European Union, which has recently admitted ten new countries and is negotiating the admission of some more in the next few years. The new facts presented here can also help analyzing the patterns of urbanization and city growth in countries with a rapid ongoing process of rural-urban migration or that have suffered natural disasters or wars.

The paper is organized as follows. In Section 2 I briefly review the existing literature that relates to my paper. Section 3 sketches a theoretical framework that helps interpreting the empirical exercises. In Section 4 I describe the dataset used and the method of sample selection. The three new empirical findings are presented in Section 5. Section 6 presents some robustness checks and finally Section 7 concludes.

\section{Related Literature}

Different papers have analyzed historical data on cities population and some properties of their distribution. Eaton and Eckstein (1997) study the evolution of the transition matrices of the largest metropolitan areas of France and Japan and conclude that they remained constant during the time interval 1876-1990 for France and 1925-1985 in the case of Japan.

Ioannides and Overman (2003) show that deviations from Gibrat's law ${ }^{1}$ are not statistically significant for the main U.S. metropolitan areas in the period 1900-1990. They estimate city growth non-parametrically and conclude that, although city growth rates seem to vary with city size, Gibrat's law does hold.

My paper differs from Eaton and Eckstein (1997) and Ioannides and Overman (2003) in several dimensions. First, I provide results for both administratively defined cities and metropolitan areas, while they only analyze the latter. The use of administratively defined cities allows me to greatly expand the number of years in the analysis. Second, the number and identity of urban agglomerations in the mentioned studies is constant over time while I allow for the possibility of adding more cities and metropolitan areas to my sample as countries urbanize. Finally, from a methodological

\footnotetext{
${ }^{1}$ This law states that the growth rate of a city's population is independent of its size. See Gibrat (1931) for a general statement of this law and Gabaix and Ioannides (2004) for a review of studies that apply it to cities.
} 
point of view I focus on the experience of city growth in each individual country and analyze two different statistics: the coefficient of skewness and the rank of the fastest growing cities. ${ }^{2}$

Chaterjee and Carlino (2001) study the evolution of employment across U.S. metropolitan areas in the postwar period and find that increases in aggregate metropolitan employment causes congestion costs to increase faster for the more dense metro areas. As it will be shown below this convexity in congestion costs is crucial in the theoretical framework that motivates my empirical exercise.

Glaeser and Gyourko (2005) document the fact that the distribution of the growth rates of cities is skewed to the right. However, they only consider the U.S. case during the period 1920-2000. My paper expands the analysis to much longer periods and a broader number of countries.

Finally, the patterns of population growth in cities that have experienced a dramatic shock has been studied in Davis and Weinstein (2002), who use the "quasi natural-experiment” provided by the strategic bombing of Japan during World War II. They interpret the remarkable recovery of Japan's urban system as evidence against random growth due to the presence of a strong mean-reverting component.

\section{Theoretical Framework}

In this section I sketch a theoretical framework that facilitates the interpretation of the empirical exercise carried on in Sections 5 and 6. Henderson and Venables (2009) and Cuberes (2009) are the only two papers that explicitly model sequential city growth i.e. the fact that cities form and grow in a sequential order, especially when urbanization is fast. The two models have in common the following facts: 1) cities grow sequentially, with the initially largest ones being the first to develop, 2) cities eventually reach an optimal/equilibrium size, and 3) this process is more pronounced the faster is the growth rate of urban population.

Henderson and Venables (2009), HV henceforth, has rich predictions on the role of different institutions in driving different types of equilibria and on housing price cycles among others. The model proposed in Cuberes (2009) is much more stylized but it captures the process of sequential city growth in a very straightforward way. For simplicity, I sketch here the main setup of the latter model, although it is worth reminding that both theories predict the three facts stated above.

\subsection{Households}

There are two cities $(A, B)$ in the model and a continuum of atomistic households that can invest in physical capital employed in these cities to produce final goods.

\footnotetext{
${ }^{2}$ Other papers that analyze the evolution of the U.S. population using long time series are Gonzalez-Val (2007), Beeson et al. (2001), Beeson and DeJong (2002), Ehrlich and Gyourko (2000), and Kim (2007).
} 
The sources of income of a representative household are wage earnings and the return on assets. Let $\omega$ be the equilibrium wage rate in this economy. ${ }^{3} z^{j}$ is the amount of assets invested by this household in city $j, j=A, B$. As it is explained in detail in Cuberes (2009), investment in physical capital is assumed to be irreversible. The household's capital income is given by $\sum_{j=A, B} r^{j} z^{j}$, where $r^{j}$ represents the net return to capital (net of congestion costs) in city $j$ and his budget constraint is therefore

$$
\sum_{j=A, B} i^{j}+c=\omega+\sum_{j=A, B} r^{j} z^{j}
$$

where $i^{j}$ is investment in city $j$ and $c$ denotes consumption. Assuming logarithmic utility, the problem of a representative household (omitting time subscripts) can then be written as:

$$
\begin{gathered}
\max \int_{0}^{\infty} e^{-\rho t} \ln (c) d t \\
\sum_{j=A, B} i^{j}+c=\omega+\sum_{j=A, B} r^{j} Z^{j} \\
i^{j} \geq 0, \forall j=A, B \\
z_{0}^{j} \text { given, } \forall j=A, B
\end{gathered}
$$

where $\rho \in(0,1)$ is the discount rate. As stated above, households face the irreversibility constraints $i^{j} \geq 0, j=A, B$. Finally, $z_{0}^{j}$ is the initial stock of assets in city $j$.

\subsection{Firms}

Firms use a constant-returns-to-scale technology to produce goods. However, each firm is subject to a positive external effect à la Romer (1986), which comes from the total stock of capital installed in the city where it operates. The production function of firm $i$ located in city $j$ is given by

$$
Y^{i j}=\left(N^{i j}\right)^{\alpha}\left(K^{i j}\right)^{1-\alpha}\left(K^{j}\right)^{\psi}
$$

where $Y^{i j}, N^{i j}$, and $K^{i j}$, respectively, represent the firm's production, labor, and capital. $K^{j}$ is the total stock of capital installed in city j, i.e. $K^{j} \equiv \sum_{i=1}^{I} K^{i j}$, and $I$ is the number of firms operating in that city. The positive parameter $\psi$ captures the size of the external effect of aggregate city capital on any firm that operates in the city.

\footnotetext{
${ }^{3}$ It is shown below that in equilibrium there is a unique national wage rate.
} 
Firms hire labor and capital at their competitive prices and sell their product in the market. Moreover, they must pay a fraction $\frac{1}{I}$ of the congestion cost $g\left(K^{j}\right)$ generated by the total stock of capital installed in the city where they operate, where $g($.$) is an$ increasing and convex function. Normalizing the price of the consumption good to one, profits of firm $i$ located in city $j$, are then given by

$$
\pi^{i j}=\left(N^{i j}\right)^{\alpha}\left(K^{i j}\right)^{1-\alpha}\left(K^{j}\right)^{\psi}-\left(r^{j}+\delta\right) g\left(K^{i j}\right)-\frac{1}{I} g\left(K^{j}\right)-\omega N^{i j}
$$

where $\delta \in(0,1)$ is the rate at which capital depreciates. The first order conditions of the firm with respect to labor and capital are, respectively:

$$
\begin{gathered}
\alpha\left(N^{i j}\right)^{\alpha-1}\left(K^{i j}\right)^{1-\alpha+\psi}=\omega \\
(1-\alpha)\left(N^{i j}\right)^{\alpha}\left(K^{i j}\right)^{\psi-\alpha}=r^{j}+\delta+g^{\prime}\left(K^{j}\right)
\end{gathered}
$$

where the symmetric equilibrium condition $K^{i j}=K^{j}, \forall i$, has been imposed. ${ }^{4}$

Since workers can migrate across cities at no cost, in equilibrium there is a unique national wage rate and from (10) labor allocates across cities to satisfy

$$
\frac{N^{A}}{N^{B}}=\left(\frac{K^{A}}{K^{B}}\right)^{\frac{1+\psi-\alpha}{1-\alpha}}
$$

From (11) one has

$$
r^{j}=f_{j}-\delta-g^{\prime}\left(K^{j}\right)
$$

where

$$
f_{j} \equiv(1-\alpha)\left(N^{j}\right)^{\alpha}\left(K^{j}\right)^{\psi-\alpha}
$$

represents the gross $M P K$ in city $j$.

\footnotetext{
${ }^{4}$ Since there are constant returns to scale at the firm level, the number and size of firms are indeterminate, and thus one can focus on the problem of a representative firm in each city and normalize $I$ to one.
} 


\subsection{Equilibrium Transition and Steady State}

Since the economy is closed and the only available asset is physical capital one has $z^{j}=k^{j}, \forall j=A, B$. The equilibrium is given by equations (12)-(14) and the market clearing condition

$$
N^{A}+N^{B}=N
$$

along with the normalization $k^{j} \equiv \frac{K^{j}}{N}, \forall j=A, B$ which was already used in the planner's problem. It is easy to show that, combining these equations, the equilibrium gross $M P K$ in city $j$ is given by

$$
f_{j}\left(k^{A}, k^{B}, N\right)=(1-\alpha) N^{\psi} \Omega\left(k^{A}, k^{B}, N\right)^{-\alpha}\left(k^{j}\right)^{\frac{\beta}{1-\alpha}-1}
$$

where

$$
\Omega\left(k^{A}, k^{B}, N\right) \equiv \sum_{j=A, B}\left(k^{j}\right)^{\frac{\beta}{1-\alpha}}
$$

The next two assumptions establish some initial conditions that initiate the dynamics of the model. Assumption 1 states that, at the initial date, city $A$ has a slightly larger stock of capital than city B.

\section{Assumption 1}

$$
K^{A}(0)=K^{B}(0)+\varepsilon
$$

where $\varepsilon$ is a small positive number.

Assumption 2 states that, at date zero, congestion costs in the city with the largest stock of capital, city $A$, are relatively small compared to the productivity gains associated with its large size. Moreover, it is assumed that investment is profitable in the smallest location, city $B$, i.e. its net $M P K$ is strictly larger than the discount rate. Obviously, this assumption also ensures that in this economy investment is profitable in city $A$ at date zero.

\section{Assumption 2}

$$
r^{A}(0)>r^{B}(0)>\rho
$$


The qualitative features of the unique equilibrium in this economy are displayed in Figures 3-5. Figure 3 plots the evolution of the equilibrium interest rates (or net returns to capital) in the two cities. In the time interval $\left(0, t_{A}\right]$, the interest rate in the city with the largest stock of capital, city $A$, increases very fast.

\section{Figure 3: Interest Rates}

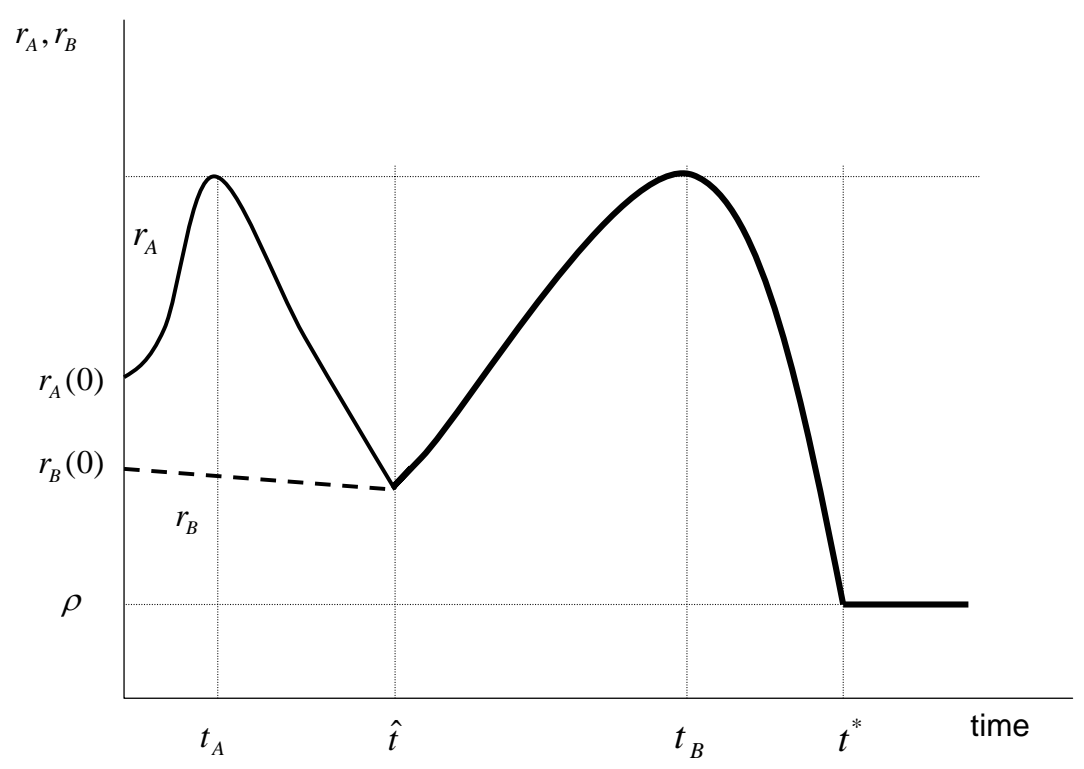

This is the case because, as a result of its initial advantage (see Assumptions 1 and 2 ) and the existence of increasing returns to scale, all the new investment in capital goes to city $A$ and labor reallocates from city $B$ to city $A$ at an increasing rate. At period $t_{A}$, congestion costs in city A start dominating increasing returns, and so the net $M P K$ in that city begins to decline rapidly. Meanwhile, the interest rate in city $B$ decreases for two reasons: First, capital depreciates there at the constant rate $\delta$ because no investment takes place in that city. Second, labor migrates to city $A$ hence further decreasing the net return to capital in city $B$.

Eventually, the economy reaches period $\hat{t}^{p}$, at which the two returns are equated. From that point on, non-arbitrage implies that these returns must remain equal to each other until the economy reaches its steady state. In order for this pattern to be optimal, one needs to make the additional assumption that in period $\hat{t}^{p}$, investment in city $B$ is still profitable, i.e. 


\section{Assumption 3}

$$
r_{B}(\hat{t})>\rho
$$

The two interest rates increase after period $\hat{t}^{p}$ until congestion costs - now in the two cities- become critical again (period $t_{B}$ ). Finally, from period $t_{B}$ until period $t^{*}$ the common interest rate smoothly converges to its steady-state value $\rho$.

Figure 4 displays the paths of the two stocks of capital. As stated above, $k^{A}$ increases between dates zero and $\hat{t}$, when the two MPKs are equalized. During this period the stock of capital in city $B$ declines as a result of the depreciation. Non-arbitrage implies that from that point on, the pattern of growth of the two cities must be such that this equality holds. Since city $A$ is relatively large and city $B$ relatively small this can only happen if the stock of capital increases in $B$ and falls in $A$. Therefore, for some periods, investment turns positive in $B$ and zero in $A$. The decline in the stock of capital in $A$ is again driven by the depreciation rate. At some point, the stocks of capital are equalized in the two cities. Let $\tilde{t}$ be the period in which this occurs. Note that this period is well defined because it is impossible to attain the steady state unless the two cities have already reached a critical level of congestion costs. Once the two stocks of capital are the same, they grow together until the economy reaches its steady state (at period $t^{*}$ ).

Figure 4: Capital

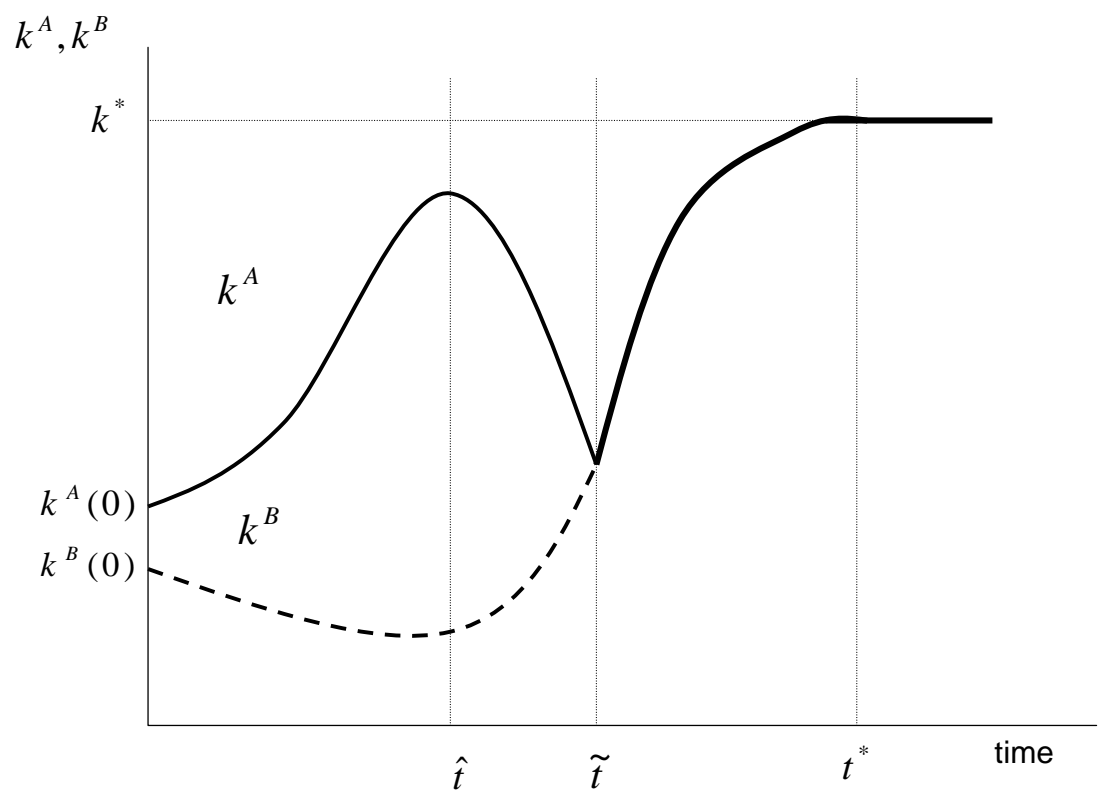


Finally, Figure 5 shows the evolution of the population in the two cities. It is clear that in the time interval $(0, \tilde{t}]$, population mimics the pattern of capital because the optimal allocation rule is given by $\frac{N^{A}}{N^{B}}=\left(\frac{K^{A}}{K^{B}}\right)^{\frac{\beta}{1-\alpha}}$. At period $\tilde{t}$, when the stocks of capital are the same in both cities, the incentives to migrate disappear and the two cities become identical in all respects. Therefore, the steady-state level of population in each city is $N^{*}=N(\tilde{t})=\frac{N}{2}$.

Figure 5: Labor

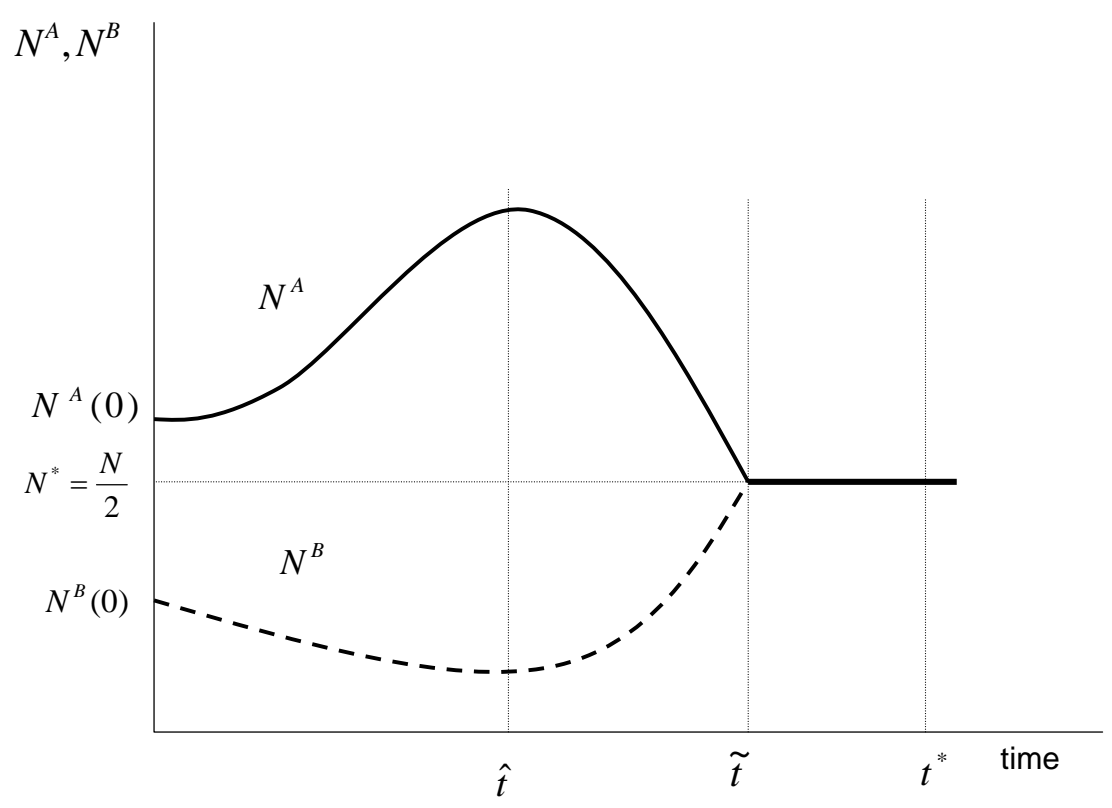

\subsubsection{The Effect of an Exogenous Population Shock}

To make the model tractable, I have so far assumed that total population $N$ is constant over time. In this section I analyze how the dynamics of the model change when the economy experiences an exogenous increase in its population. One can interpret this experiment as a rapid increase in the country's urbanization process. Such rapid changes in urban population are not uncommon in the data, especially in developing countries. ${ }^{5}$ The next proposition shows that increasing returns imply that the gross $M P K$ in both cities increases as a result of the shock.

\footnotetext{
${ }^{5}$ Henderson and Wang (2007) document that the urbanization rate is most rapid at low-income levels and then tails off as countries become "fully urbanized."
} 
Proposition 3: An exogenous increase in population $N$ increases the gross $M P K$ in the two cities.

Proof: Using the fact that $k^{j} \equiv \frac{K^{j}}{N}$ the gross $M P K$ in city $j$ (7) can be expressed as

$$
f_{j}=\alpha N^{\alpha} \hat{\Omega}\left(K^{A}, K^{B}\right)^{-\alpha}\left(K^{j}\right)^{\frac{\beta}{1-\alpha}-1}
$$

where

$$
\hat{\Omega}\left(K^{A}, K^{B}\right)=\sum_{j=A, B}\left(K^{j}\right)^{\frac{\beta}{1-\alpha}}
$$

Since the term $\hat{\Omega}\left(K^{A}, K^{B}\right)^{-\alpha}\left(K^{j}\right)^{\frac{\beta}{1-\alpha}-1}$ is independent of $N$ one has that the effect of an increase in $N$ on the $M P K$ of city $j$ is

$$
\frac{\partial f_{j}}{\partial N}=\alpha^{2} N^{\alpha-1} \hat{\Omega}\left(K^{A}, K^{B}\right)^{-\alpha}\left(K^{j}\right)^{\frac{\beta}{1-\alpha}-1}>0
$$

Q.E.D.

Proposition 4 states that increasing returns also imply that the population shock increases the gross return to capital more in the largest city than in the smallest one.

Proposition 4: An exogenous increase in population $N$ increases the gross $M P K$ in the largest city more than in the smallest one.

Proof: Suppose the opposite is true i.e. $k^{A}>k^{B}$ but $\frac{\partial f_{A}}{\partial N} \leq \frac{\partial f_{B}}{\partial N}$. This implies $\left(\frac{k^{A}}{k^{B}}\right)^{\frac{\beta}{1-\alpha}-1} \leq 1$ which is a contradiction since $\alpha+\beta>1$ and $k^{A}>k^{B}$. Q.E.D.

Finally, the next corollary shows that any increase in $N$ is in general associated with a more pronounced process of sequential city growth. 
Corollary: An exogenous increase in population $N$ at any period $t \leq \hat{t}$ accelerates the process of sequential city growth

Proof: Suppose that the shock occurs at $t \in(0, \hat{t}]$. In equilibrium, city $A$ is the only one growing in this time interval and from Propositions 3 and 4 the shock makes city $A$ grow faster. Moreover, its marginal congestion costs $g^{\prime}\left(K^{A}\right)$ increase with $N$, since $K^{A}=k^{A} N$. These two forces imply that $\hat{t}$ must now be lower i.e. the period at which the population of city $B$ starts growing is reached faster and so the process of sequential growth is more pronounced. Q.E.D.

In the context of two cities, if the shock takes place at any $t>\hat{t}$, the speed of sequential growth would not be affected. Consider first the case in which the shock occurs at $t \in(\hat{t}, \tilde{t}]$. Since in this time interval city $A$ is too congested, most of the additional population (and hence investment) will locate in city $B$ until this city reaches its steady state. Population would optimally be allocated between the two cities, but the model does not allow for the creation of a (potentially optimal) third city. So city $B$ grows faster as a consequence of the shock; however this has no implications for sequential growth because there is no "rank 3" city to start growing. If total population increases after the economy's steady-state has been reached, the additional population is split evenly between the two cities because at that point they are identical. Therefore, there is no change in the speed of sequential growth either.

If one extends the model to $M>2$ cities (see Section 4), an increase in total population translates into faster sequential growth unless if this shock takes place after the $M-1$ city experiences its period of solo growth. For $M$ large enough, the probability of the shock occurring in this time interval is arbitrarily small, and so the model predicts that, in most cases, an increase in total population implies faster sequential city growth.

\subsection{Testable Implications of the Model}

The model sketched above has clear testable implications. The first one is that from Proposition 1 the population of one city grows much faster than the rest at each point in time during the transition to the steady state (see Figures 2 and 4). If one thinks of the case with $M>2$ cities this implies that the coefficient of skewness of cities growth rates must be positive along this transition.

Second, at each point in time, the fastest growing city is the largest one conditional on the fact that congestion costs are not too large in that city, i.e. cities grow in a precise sequential order. This corresponds to the second empirical fact provided below. 
Finally, any increase in total population increases the gross marginal product of capital in both cities but the increase is strictly larger in the largest one. ${ }^{6}$ This implies that the rank of the fastest growing cities should increase faster when population increases.

\section{The Data}

There currently exist three comprehensive datasets for international comparisons of population of urban agglomerations over long intervals of time. The first one is from Vernon Henderson and it contains data on metropolitan areas (henceforth MAs) in different countries during the period 1960-2000. The second one, by Thomas Brinkhoff, presents information on the population of various administratively defined cities (cities henceforth) in 79 countries during the period 1970-2000. Finally, the most comprehensive dataset, by Jan Lahmeyer, has the size of the largest cities in a very large number countries. For many countries, he covers the period 1790-2000.

This paper combines city data at a decade frequency from 54 countries from the Lahmeyer's and Brinkhoff's datasets and data on the metropolitan areas of 115 countries from Henderson. A list of the countries and decades studied here is presented in Appendix A.

Using the two units of analysis is important for several reasons. First, as Eeckhout (2004) argues, the choice of unit depends on the research objective. He also states that “...in past research both MAs and cities have proved to be useful and relevant economic units, and both have been studied extensively."7 On the other hand, in the theoretical framework of Section 3 it is difficult to determine whether the externalities and congestion costs apply more at the local or global level and so the use of both units seems to be justified. For instance, in HV, firms in a city produce a single homogenous good with internal constant returns to scale but subject to "citywide scale externalities". These externalities come from the fact that workers benefit from interaction with each other. Congestion costs in their model come from commuting costs. Again it is hard to know the extent to which these forces operate more at the city or the MA level and hence using the two units is reasonable.

\subsection{Selection of Relevant Cities}

In this subsection I follow Henderson and Wang (2007)- HW henceforth- to select a sample of cities that is comparable across time and countries. They consider metropolitan

\footnotetext{
${ }^{6}$ The model does not distinguish between total and urban population because the rural sector is not explicitly modeled. In that sense one can interpret the theory as a purely urban model in which cities compete for resources against each other. Therefore, in the empirical exercise I interpret increases in $N$ as increases in urban population. The rural sector is explicitly modeled in HV and so in their context is even clearer that the relevant trigger of the dynamics is urban population and not total one.

${ }^{7}$ See also Glaeser et al. (1995) for a discussion on the use of cities versus MAs.
} 
areas in the period 1960-2000 and choose a cutoff of 100,000 based on Black and Henderson (2003) who state

"The 100,000 cutoff is chosen for practical reasons- it is the cutoff employed by many countries. None has a higher cutoff and most do not provide consistent data over time on cities below 100,000. Even USA metro areas which in theory have a cutoff of 50,000, in practice only include comprehensively urban counties with over 85,000 urban residents."

I use the same cutoff used in HW in the exercises that involve MAs. For the city data the choice must be different for two obvious reasons. The first one is that administratively defined cities tend to be considerably smaller units. ${ }^{8}$ Second, my sample of cities expands back to 1800 when most cities were much smaller than in 1950, the year at which the HW sample begins.

In order to select an appropriate cutoff I focus on the distribution of city sizes in the United States in $1790 .^{9}$ The median city size in that year is 5,077 and its average is 8,402.3. Dividing both numbers gives us a threshold of 0.6. Next, following HW, I select the cities that in each decade satisfy the following inequality:

$$
\frac{N_{i j t}}{\bar{N}_{j t}}>\frac{N_{\text {med }, U S, 1790}}{\bar{N}_{U S, 1790}}=0.6
$$

where $N_{i j t}$ is the population of city $i$ in country $j$ and period $t$, and $\bar{N}_{j t}$ is the average city population of country $j$ in that period. $N_{\text {med,US,1790 }}$ and $\bar{N}_{U S, 1790}$ denote the median and the average city population of the United States in 1790 respectively. ${ }^{10}$

A direct consequence of this methodology is that, as happens in HW, the number of cities and MAs increases as time goes by. Below it is described how I control for this in the regression analysis.

\section{Empirical Analysis}

In this section I document the three new empirical facts described above: the right skewness of the cross section of cities growth rates, the increasing rank of the fastest

\footnotetext{
${ }^{8}$ For instance, using the definition of an administratively defined city, New York had a population of $8,008,278$ in the year 2000. Its MA however includes a much larger geographical area and so the figure becomes 21,199,865.

${ }^{9}$ I have ran multiple robustness checks choosing different countries and years as a reference point- and hence different cutoffs- and, although the composition and size of the resulting samples change, the qualitative results do not vary much. Some of these exercises are reported in Section 6 of the paper. For a discussion on truncation points see Eeckhout (2008).

${ }^{10}$ In HW the corresponding ratio is the result of dividing 100,000 by the average size of world cities in $1960(495,101)$ giving a ratio of 0.202 .
} 
growing cities over time, and the positive impact of urban growth on this sequential process.

\subsection{Right Skewness of Cities Growth Rates}

In order to test the hypothesis that in each decade a few cities grow much faster than the rest I calculate the coefficient of skewness for each cross section of cities growth rates. Positive (negative) skewness indicates a distribution with an asymmetric tail extending toward more positive (negative) values.

For cities my sample consists of 536 country-decades observations. However, in eighteen cases the number of cities is equal to or lower than two and so it is not possible to calculate this coefficient. In $89 \%$ of the remaining cases this coefficient is strictly positive. Figure 5 in Appendix $\mathrm{C}$ shows a histogram of these skewness coefficients.

Figure 1: Histogram of the Coefficient of Skewness of Cities’ Growth Rates

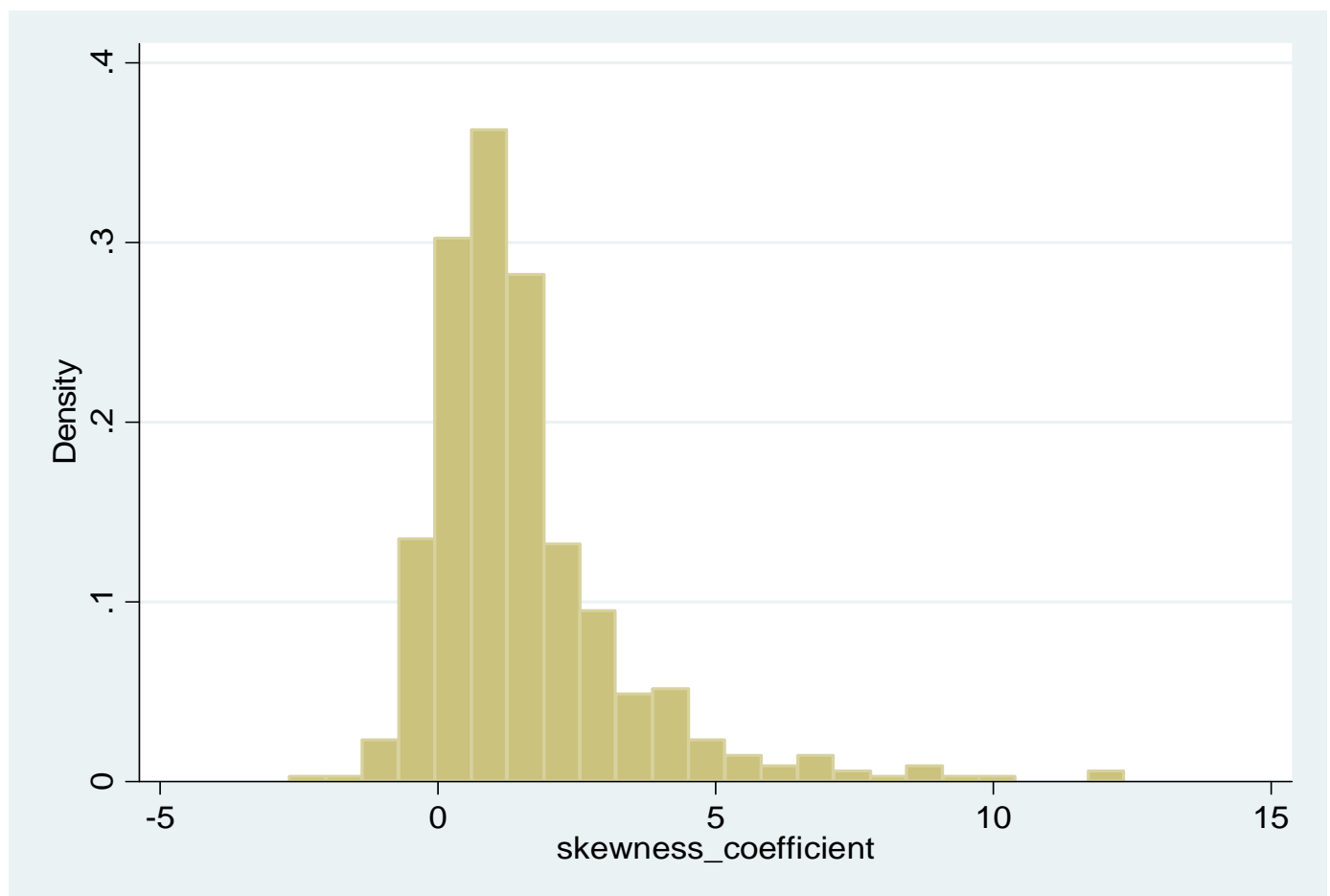

I next run a test to determine how often this positive coefficient is statistically significant. This normality test requires a minimum of eight observations and its null hypothesis is that the distribution of the data is normal. ${ }^{11}$ In $73 \%$ of the cases this coefficient is positive and significant at conventional levels. This represents a remarkably

\footnotetext{
${ }^{11}$ More details on this test can be found in D'Agostino et al. (1990) and in Royston (1991).
} 
high percentage given the fact that the number of observations is quite small in many periods and countries.

For MAs the total number country-decade observations is 460 . In $77 \%$ of the 343 cases in which it is possible to calculate it the coefficient of skewness is positive. When I run the previous test the percentage of significant right skewness is 63\%, a figure lower than the one obtained using city data but still fairly large. A histogram of the skewness coefficients for the MAs cross sections is displayed in Figure 6 of Appendix C.

Figure 2: Histogram of the Coefficient of Skewness of MAs’ Growth Rates

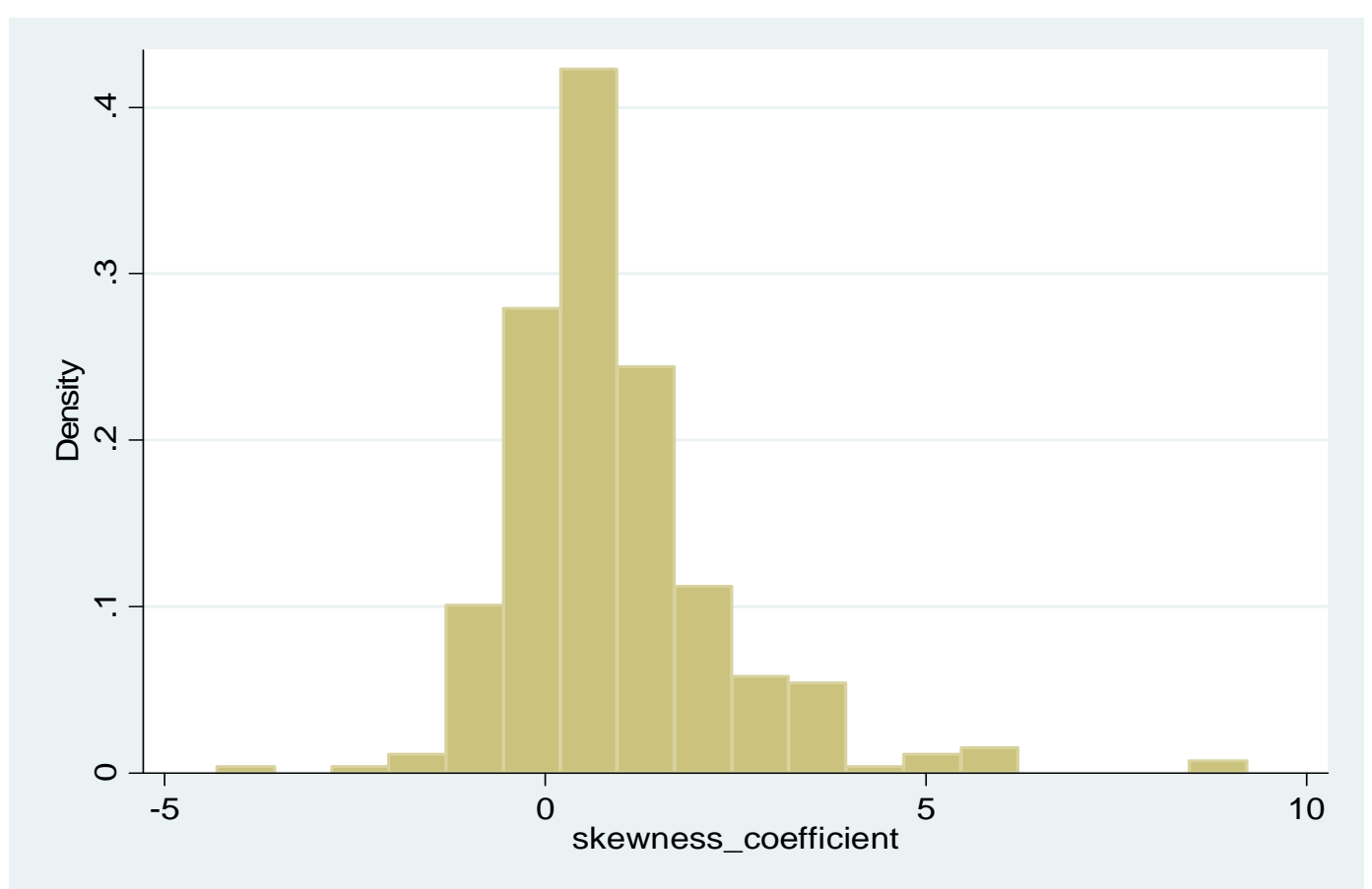

The conclusion of this exercise is that there is very strong evidence indicating that, within a country, a few cities tend to grow much faster than the rest in most decades and that this finding is statistically significant using data on both administratively defined cities and MAs.

\subsection{Rank of the Fastest Growing Cities}

In this subsection I expand the previous finding and ask whether one can say something about the identity of the fastest growing cities in each decade. According to the theory sketched in Section 3, these cities should be the largest ones- in terms of population- conditional on the fact that they have not yet reached a critical size. 
I begin by ranking cities by size (in terms of population) on every decade, with the largest city having rank 1, the second largest having rank 2, and so on. It follows from the theory of sequential city growth that the rank of the fastest growing cities should exhibit a positive time trend i.e. the initially largest city should be the one that grows the fastest, then the second largest one, then the third one, and so on.

In order to test this idea I calculate for each country-decade the $75^{\text {th }}$ percentile of cities growth rates and consider the cities which growth rate is larger or equal to this cutoff. $^{12}$ I refer to these cities as "fast-growers" in that decade and I proceed to calculate their average population rank.

\subsubsection{An Example}

Here I provide an example that clarifies what exactly it is meant by "the rank of the fastest growing cities". Consider the population of French cities in the years 1851 and 1861 from the Lahmeyer's dataset. Table 1 presents this data ordering cities by size -in increasing order- in 1861. The fourth column illustrates the method of sample selection employed throughout the paper. Only those cities which relative population (relative to the country's average in 1861) is strictly larger than 0.6 are selected. In this particular example, Toulouse is the last city that satisfies this constraint. The growth rates of cities population between these two years are reported in the last column. In this example the number of observations in the 1851-1861 year-pair is 7 and the skewness coefficient of cities growth rates is 0.3 .

Table1: Rank and Growth Rate of the Largest French Cities in 1861

\begin{tabular}{lccccc}
\hline \multicolumn{1}{c}{ City } & Population in 1851 & Population in 1861 & Rank in 1861 & Growth Rate & Ratio popl avg in 1861 \\
\hline Paris & $1,053,300$ & $1,696,100$ & 1 & 0.61 & 9.25 \\
Lyon & 177,200 & 318,800 & 2 & 0.8 & 1.74 \\
Marseille & 193,300 & 260,900 & 3 & 0.35 & 1.42 \\
Bourdeaux & 130,900 & 162,800 & 4 & 0.24 & 0.89 \\
Lille & 75,800 & 131,800 & 5 & 0.74 & 0.72 \\
Nantes & 96,400 & 113,600 & 6 & 0.18 & 0.62 \\
Toulouse & 94,200 & 113,200 & 7 & 0.2 & 0.62 \\
\hline
\end{tabular}

Table 2 uses the subsample of cities whose growth rate is strictly larger than the $75^{\text {th }}$ percentile of the growth rates in Table 1 . In this example this percentile is equal to 0.739 and so only the cities of Lyon and Lille are classified as "fast-growers". Finally, in the third column of Table 2 I calculate the average 1861 rank of these two cities, which in

${ }^{12}$ This exercise has been done with different cutoffs $\left(70^{\text {th }}\right.$ and $80^{\text {th }}$ percentiles) and the results are very similar. See Section 6. 
this example turns out to be 3.5. I then repeat this routine for every decade-pair for which the country has available data and so I am able to construct a time series of the rank of the fastest growing cities for each country.

Table 2: Average Rank of the Fastest Growing Cities in 1861’s France

\begin{tabular}{lcc}
\hline Fastest 25\% Cities & Rank in 1861 & Average Rank of Fastest 25\% Cities \\
\hline Lyon & 2 & \\
Lille & 5 & 3.5 \\
\hline
\end{tabular}

\subsubsection{Evolution of the Rank over Time}

In this subsection I test whether the rank of the fastest growing cities described above tends to increase over time. It is important to notice that if total and/or urban population grow over time the method of selecting the "relevant" cities described in Section 4.1 has the obvious consequence of choosing an increasing number of cities as time goes by. This is relevant for my test since the finding that the rank of the fastest growing cities has a positive time trend may in large part reflect the fact that- by construction- in each subsequent decade there are more cities that can potentially grow fast. To control for this I include the number of cities on each decade and country as a control variable. I hence estimate the following panel data regression:

$$
\log r f_{i t}=\alpha+\beta_{1} \log t+\beta_{2} \log N_{i t}+\varepsilon_{i t}
$$

where $r f_{i t}$ and $N_{i t}$ are the average rank of the $25 \%$ fastest growing cities (or MAs) and the number of cities (or MAs) in country $i$ and period $t$, respectively. The variable $t$ measures time and $\varepsilon_{i t}$ is a standard error term.

I estimate (18) using fixed effects to control for unobservable country time invariant factors that may affect the evolution of the rank over time. Examples of such unobservable variables are aspects of geography and culture that may have an impact on a country's city growth process. ${ }^{13}$ Table 3 shows the estimates of this regression. ${ }^{14}$

\footnotetext{
${ }^{13}$ Davis and Henderson (2003) also use fixed effects in their study of the determinants of urban primacy.

${ }^{14}$ In all the regressions I cluster the errors by country to account for possible serial correlation within countries. The results are qualitatively similar if one estimates (18) using pooled OLS. In those regressions I also include the number of years per country as a regressor. To save space I only present the fixed effects estimates here.
} 
Table 3: A Regression of the Average Rank of the 25\% Fastest Growing Cities on Time and Number of Cities

\begin{tabular}{lcc}
\hline & $(\mathbf{1})$ & $\mathbf{( 2 )}$ \\
\hline log time & $\begin{array}{c}0.668^{\star \star \star} \\
(0.07)\end{array}$ & $\begin{array}{c}0.063^{\star \star} \\
(0.03)\end{array}$ \\
log number cities & & $\begin{array}{c}0.923^{\star \star \star} \\
(0.03)\end{array}$ \\
& & \\
constant & $\begin{array}{c}1.317^{\star \star \star} \\
(0.11)\end{array}$ & $\begin{array}{c}-0.478^{\star \star \star} \\
(0.06)\end{array}$ \\
& & \\
$\mathrm{R}^{2}$ & 0.331 & 0.841 \\
$\mathrm{~N}$ & 536 & 536 \\
\hline
\end{tabular}

The first column of Table 3 shows that the rank of the fastest growing cities clearly increases as time goes by. Importantly, the positive sign of the trend coefficient remains significant even when one controls for the fact that the number of available cities increases as time goes by (column 2). Although including the number of cities has an important effect- the size of the time coefficient drops by a factor of ten when I include this regressor- the time trend is still significantly positive.

Table 4 repeats the previous exercise for metropolitan areas. Again the results strongly support the hypothesis that the rank of the fastest growing MAs exhibits a positive time trend. Notice that the size of the coefficient in the first specification (column 1) is lower than in the case of cities, probably reflecting the fact that using the Henderson dataset one has only forty years of data per country. The drastic reduction on the time span is also reflected in the much lower $R^{2}$ coefficients. As in Table 3 the inclusion of the number of MAs as a regressor has a large effect on the magnitude of the time trend although it remains statistically significant. 
Table 4: A Regression of the Average Rank of the 25\% Fastest Growing MAs on Time and Number of Cities

\begin{tabular}{lcc}
\hline & $\mathbf{( 1 )}$ & $\mathbf{( 2 )}$ \\
\hline log time & $0.231^{\star \star \star}$ & $0.078^{\star}$ \\
& $(0.04)$ & $(0.04)$ \\
log number MAs & & $\begin{array}{c}0.617^{\star \star \star} \\
(0.07)\end{array}$ \\
constant & & 0.131 \\
& $\begin{array}{c}1.22^{\star \star \star} \\
(0.03)\end{array}$ & $(0.13)$ \\
$\mathrm{R}^{2}$ & & \\
$\mathrm{~N}$ & 0.093 & 0.311 \\
\hline
\end{tabular}

Another piece of evidence supporting the existence of a very clear positive trend on the rank of the fastest growing cities is that in $96 \%$ of the countries the average growth rate of this measure is strictly positive. Using data on MAs this percentage is $76 \%$.

The results shown in this section clearly indicate that the rank of the cities that grow the fastest significantly increases over time, as it is predicted by the theory described in Section 3. As in the previous exercise this result strongly holds for both administratively defined cities and metropolitan areas.

\subsubsection{Growth of Urban Population and the Rank of the Fastest Growing Cities}

The last test I run is whether the rank of the fastest growing cities grows more rapidly in periods in which urban population grows faster than usual. This is a prediction of the model sketched in Section 3- more population pressure on the existing cities tends to enhance sequential city growth.

Urban population is defined here as the sum of the population of the cities (or MAs) that are above the $0.6(0.202)$ cutoff defined in Section 4.1. For instance, in the example of Section 5.2.1 urban population in France in 1861 is 2,797,200.

I begin by calculating the average growth rate of the rank statistic in periods of unusual rapid growth - defined as a growth rate of urbanization above the country's average- and compare it with the average in the rest of periods. Table 5 shows that this average is much larger in the 210 episodes of rapid urbanization than in the rest of periods, suggesting that sequential growth tends to be more relevant during these periods. In the robustness section I show that this difference is statistically significant. 
Table 5: Average Growth Rate of the Rank of the 25\% Fastest Growing Cities in Periods of Fast and Slow Urban Growth

\begin{tabular}{lcc}
\hline & Average Growth Rate of Rank & $\mathbf{N}$ \\
\hline fast urban growth & 1.05 & 210 \\
slow urban growth & 0.17 & 322 \\
\hline
\end{tabular}

A more direct way to analyze the relationship between the growth rate of the rank of the fastest growing cities (or MAs) and the growth rate of urban population is to regress one on the other. However, as argued above, the relationship between these two variables may be driven by the fact that, by construction, the number of observations increases over time in our sample. To take this into account I include the growth rate in the number of cities (or MAs) as an additional regressor. The specification I estimate is then

$$
g_{R_{i t}}=\alpha+\beta_{1} g_{U_{i t}}+\beta_{2} g_{N_{i t}}+u_{i t}
$$

where $g_{R_{i t}}$ and $g_{N_{i t}}$ denote the growth rate of the rank of the fastest growing cities (or MAs) and the growth rate in the number of cities (or MAs) in country $i$ and period $t$ respectively. $g_{U_{i t}}$ is the growth rate of its urban population and $u_{i t}$ denotes a standard error term.

The results of estimating (9) using city data and fixed effects are shown in Table 6. ${ }^{15}$ In both specifications the coefficient on urban growth is significantly positive. Controlling for the growth rate in the number of available cities in the sample has the expected effect of lowering the magnitude of the coefficient on urban growth, although its significance is preserved.

\footnotetext{
${ }^{15}$ The pooled OLS results are similar and available upon request.
} 
Table 6: A Regression of the Growth Rate of the Average Rank of the 25\% Fastest Growing Cities on the Growth Rate of Urban Population and the Growth Rate in the Number of Cities

\begin{tabular}{lcc}
\hline & $\mathbf{( 1 )}$ & $\mathbf{( 2 )}$ \\
\hline growth rate of urban pop & $\begin{array}{c}1.322^{\star \star \star} \\
(0.18)\end{array}$ & $\begin{array}{c}0.598^{\star \star \star} \\
(0.22)\end{array}$ \\
growth rate of number of cities & & $\begin{array}{c}0.81^{\star \star \star} \\
(0.04)\end{array}$ \\
constant & & \\
& -0.002 & -0.046 \\
$\mathrm{R}^{2}$ & $(0.07)$ & $(0.09)$ \\
$\mathrm{N}$ & & \\
\hline
\end{tabular}

The results of this test for MAs are displayed in Tables 7 and 8. The first one indicates that using this definition it is still the case that the average growth rate of the rank 75 is larger in periods of fast urbanization ( 0.47 versus 0.23$)$. The regression results show that the positive relationship between the rank statistic and urban growth is significant at the $1 \%$ level even after controlling for the growth rate in the number of MAs. It is interesting to notice that, as happened in the second test (Section 5.2.2) the magnitude of the coefficient on fast urban growth is smaller than when one uses data on cities. This is the case also when one includes the growth rate in the number of cities (or MAs) as a regressor. ${ }^{16}$

Table 7: Average Growth Rate of the Rank of the 25\% Fastest Growing MAs in Periods of Fast and Slow Urban Growth

\begin{tabular}{lcc}
\hline & Average Growth Rate of Rank & N \\
\hline fast urban growth & 0.47 & 198 \\
slow urban growth & 0.23 & 245 \\
\hline
\end{tabular}

\footnotetext{
${ }^{16}$ It is hard to disentangle if these differences (and those between Tables 3 and 4) are due to the use of different unit of analysis (MAs versus administratively defined cities) or to the fact that for MAs one can only find reliable data for the period 1960-2000 in most countries.
} 
Table 8: A Regression of the Growth Rate of the Average Rank of the 25\% Fastest Growing MAs on the Growth Rate of Urban Population and the Growth Rate in the Number of MAs

\begin{tabular}{lcc}
\hline & $\mathbf{( 1 )}$ & $\mathbf{( 2 )}$ \\
\hline growth rate of urban pop & $0.16^{\star \star}$ & $0.238^{\star \star \star}$ \\
& $(0.08)$ & $(0.06)$ \\
growth rate of number of MAs & & $0.728^{\star \star \star}$ \\
& & $(0.2)$ \\
constant & $0.254^{\star \star \star}$ & 0.072 \\
& $(0.04)$ & $(0.05)$ \\
$\mathrm{R}^{2}$ & & \\
$\mathrm{~N}$ & 0.007 & 0.193 \\
\hline
\end{tabular}

In order to facilitate the interpretation of this finding Appendix B plots the growth rate of urban population in each decade, the country's average growth rate of urban population and the growth rate of the 75-rank statistic. The positive relationship between urban growth and rank growth it is apparent in most cases. Consider, for instance, the case of Algeria. The growth rate of the rank of the fastest growing cities exhibits considerable variation but its evolution is extremely close to that of the growth rate of urban population, especially after 1950. Bangladesh, Brazil, Hungary, and Sweden are some other cases in which the relationship between the two variables is extremely close. Note that, as it was mentioned above the average growth rate of the rank is positive in almost all countries.

The corresponding figures for MAs are displayed in Appendix C. The fact that one has only four decades per country makes the result less visible. However, it is apparent that in most cases the growth rate of urban population and that of the rank move very closely. Some clear examples of this relationship are Egypt, France, Honduras, Mozambique, Paraguay, and Portugal.

The estimates, statistics, and plots shown in this section constitute very strong evidence in favor of the importance of rapid urban growth on the process of sequential city growth. 


\section{Robustness Checks}

In this section I provide several robustness checks that help confirming the strength of my empirical results.

\subsection{Different Thresholds to Select Cities}

It is apparent from Section 4.1 that the cutoff used to select the relevant sample of cities is inevitably arbitrary. ${ }^{17}$ The following two tables are the equivalent to Tables 3 and 6 using a different cutoff to select the sample of cities. The specific cutoff used here is zero, i.e. all available cities are selected.

Table 9: A Regression of the Average Rank of the 25\% Fastest Growing Cities on Time and Number of Cities. Zero Cutoff for City Selection.

\begin{tabular}{lcc}
\hline & $(\mathbf{1})$ & $\mathbf{( 2 )}$ \\
\hline log time & $\begin{array}{c}0.763^{\star \star \star} \\
(0.07)\end{array}$ & $\begin{array}{c}0.092^{\star \star \star} \\
(0.03)\end{array}$ \\
log number cities & & $\begin{array}{c}0.86^{\star \star \star} \\
(0.02)\end{array}$ \\
constant & & $\begin{array}{c}1.764^{\star \star \star} \\
(0.11)\end{array}$ \\
& $\begin{array}{c}-0.325^{\star \star \star} \\
(0.08)\end{array}$ \\
$\mathrm{R}^{2}$ & 0.38 & 0.834 \\
$\mathrm{~N}$ & 536 & 536 \\
\hline
\end{tabular}

${ }^{17}$ This arbitrariness is less conspicuous using the Henderson dataset on MAs. See Henderson and Wang (2007) for more details. 
Table 10: A Regression of the Growth Rate of the Average Rank of the 25\% Fastest Growing Cities on the Growth Rate of Urban Population and the Growth Rate in the Number of Cities

\begin{tabular}{lcc}
\hline & $\mathbf{( 1 )}$ & $\mathbf{( 2 )}$ \\
\hline growth rate of urban pop & $1.34^{\star *}$ & $1.279^{\star *}$ \\
& $(0.59)$ & $(0.57)$ \\
growth rate of number of cities & & $\begin{array}{c}0.581^{\star \star *} \\
(0.03)\end{array}$ \\
constant & & \\
& 0.119 & -0.188 \\
$\mathrm{R}^{2}$ & $(0.23)$ & $(0.22)$ \\
$\mathrm{N}$ & & \\
\hline
\end{tabular}

As it is clear from the estimates, the qualitative results of the exercise do not change. The rank of the fastest growing cities significantly increases over time and its growth rate is faster in periods of rapid growth in urban population. The magnitude of the coefficients does not differ much from the 0.6 cutoff used in the main text. Moreover, it is still the case that almost all of the country-decade cities growth rates exhibit significant right skewness. The same is true if one chooses a cutoff larger than 0.6.

\subsection{Different Percentiles to Select Fast Cities}

Here I use different percentiles in my definition of what constitutes a "fast-growing" city. In the main text a city is a "fast-grower" in a given decade if its growth rate is above the $75^{\text {th }}$ percentile of the growth rates of cities in that country and decade. Below I reproduce Tables 3 and 6 (for cities) and 4 and 8 (for MAs) using the $70^{\text {th }}$ and $80^{\text {th }}$ percentiles of the growth rates of cities.

Tables 11-14 show the results that correspond to choosing the $70^{\text {th }}$ percentile of the of cities growth rates, i.e. the $30 \%$ fastest growing cities. The magnitude of all the relevant coefficients increases with respect to the ones I obtained using the $75^{\text {th }}$ percentile. In Tables 15-18 I do the same using the $80^{\text {th }}$ percentile and, although the size of the coefficients is reduced they remain significant, with the exception of the time trend in specification (2) of Table 15. 
Table 11: A Regression of the Average Rank of the 30\% Fastest Growing Cities on Time and Number of Cities

\begin{tabular}{lcc}
\hline & $\mathbf{( 1 )}$ & $\mathbf{( 2 )}$ \\
\hline log time & $\begin{array}{c}0.672^{\star \star \star} \\
(0.07)\end{array}$ & $\begin{array}{c}0.072^{\star \star \star} \\
(0.02)\end{array}$ \\
log number cities & & $\begin{array}{c}0.915^{\star \star \star} \\
(0.03)\end{array}$ \\
constant & $\begin{array}{c}1.315^{\star \star \star} \\
(0.11)\end{array}$ & $\begin{array}{c}-0.464^{\star \star \star} \\
(0.06)\end{array}$ \\
$\mathrm{R}^{2}$ & 0.349 & 0.871 \\
$\mathrm{~N}$ & 536 & 536 \\
\hline
\end{tabular}

Table 12: A Regression of the Growth Rate of the Average Rank of the 30\% Fastest Growing Cities on the Growth Rate of Urban Population and the Growth Rate in the Number of Cities

\begin{tabular}{lcc}
\hline & $\mathbf{( 1 )}$ & $\mathbf{( 2 )}$ \\
\hline growth rate of urban pop & $1.315^{\star \star \star}$ & $0.679^{\star \star}$ \\
& $(0.21)$ & $(0.27)$ \\
growth rate of number of cities & & $0.712^{\star \star \star}$ \\
& & $(0.05)$ \\
constant & & \\
& -0.037 & -0.075 \\
$\mathrm{R}^{2}$ & $(0.08)$ & $(0.09)$ \\
$\mathrm{N}$ & & \\
\hline
\end{tabular}


Table 13: A Regression of the Average Rank of the 30\% Fastest Growing MAs on Time and Number of MAs

\begin{tabular}{|c|c|c|}
\hline & (1) & (2) \\
\hline log time & $\begin{array}{c}0.225^{\star \star \star} \\
(0.04)\end{array}$ & $\begin{array}{l}0.07^{\star} \\
(0.03)\end{array}$ \\
\hline log number MAs & & $\begin{array}{c}0.628^{\star \star * *} \\
(0.07)\end{array}$ \\
\hline constant & $\begin{array}{c}1.242^{\star \star \star} \\
(0.03)\end{array}$ & $\begin{array}{l}0.134 \\
(0.12)\end{array}$ \\
\hline $\mathrm{R}^{2}$ & 0.102 & 0.364 \\
\hline $\mathrm{N}$ & 448 & 448 \\
\hline
\end{tabular}

Table 14: A Regression of the Growth Rate of the Average Rank of the 30\% Fastest Growing MAs on the Growth Rate of Urban Population and the Growth Rate in the Number of MAs

\begin{tabular}{lcc}
\hline & $\mathbf{( 1 )}$ & $\mathbf{( 2 )}$ \\
\hline growth rate of urban pop & $0.165^{\star \star}$ & $0.238^{\star \star \star}$ \\
& $(0.08)$ & $(0.06)$ \\
growth rate of number of MAs & & $\begin{array}{c}0.687^{\star \star \star} \\
(0.18)\end{array}$ \\
constant & & \\
& $0.2^{\star \star \star}$ & 0.033 \\
$\mathrm{R}^{2}$ & $(0.03)$ & $(0.04)$ \\
$\mathrm{N}$ & & \\
\hline
\end{tabular}


Table 15: A Regression of the Average Rank of the 20\% Fastest Growing Cities on Time and Number of Cities

\begin{tabular}{lcc}
\hline & $\mathbf{( 1 )}$ & $\mathbf{( 2 )}$ \\
\hline log time & $0.659^{\star \star \star}$ & 0.044 \\
& $(0.07)$ & $(0.03)$ \\
log number cities & & $\begin{array}{c}0.939^{\star \star \star} \\
(0.03)\end{array}$ \\
constant & & $\begin{array}{c}-0.505^{\star \star \star} \\
\left(.32^{\star \star \star}\right. \\
\end{array}$ \\
& $(0.11)$ & $(0.07)$ \\
$\mathrm{R}^{2}$ & 0.305 & 0.804 \\
$\mathrm{~N}$ & 536 & 536 \\
\hline
\end{tabular}

Table 16: A Regression of the Growth Rate of the Average Rank of the 20\% Fastest Growing Cities on the Growth Rate of Urban Population and the Growth Rate in the Number of Cities

\begin{tabular}{lcc}
\hline growth rate of urban pop & $(\mathbf{1})$ & $(\mathbf{2})$ \\
\cline { 2 - 2 } & $\begin{array}{c}1.443^{\star \star \star} \\
(0.26)\end{array}$ & $\begin{array}{c}0.704^{\star \star} \\
(0.33)\end{array}$ \\
growth rate of number of cities & & $\begin{array}{c}0.828^{\star \star \star} \\
(0.07)\end{array}$ \\
& & \\
constant & 0.02 & -0.025 \\
& $(0.1)$ & $(0.12)$ \\
$\mathrm{R}^{2}$ & & \\
$\mathrm{~N}$ & 0.201 & 0.515 \\
\hline
\end{tabular}


Table 17: A Regression of the Average Rank of the 20\% Fastest Growing MAs on Time and Number of MAs

\begin{tabular}{lcc}
\hline & $\mathbf{( 1 )}$ & $\mathbf{( 2 )}$ \\
\hline log time & $0.226^{\star \star \star}$ & $0.078^{\star}$ \\
& $(0.05)$ & $(0.04)$ \\
log number MAs & & $0.6^{\star \star \star}$ \\
& & $(0.08)$ \\
constant & $1.197^{\star \star \star}$ & 0.139 \\
& $(0.04)$ & $(0.15)$ \\
$\mathrm{R}^{2}$ & & \\
$\mathrm{~N}$ & 0.074 & 0.245 \\
\hline
\end{tabular}

Table 18: A Regression of the Growth Rate of the Average Rank of the 20\% Fastest Growing MAs on the Growth Rate of Urban Population and the Growth Rate in the Number of MAs

\begin{tabular}{lcc}
\hline & $(\mathbf{1})$ & $(\mathbf{2})$ \\
\hline growth rate of urban pop & $0.274^{\star \star \star}$ & $0.354^{\star \star \star}$ \\
& $(0.1)$ & $(0.08)$ \\
growth rate of number of MAs & & $0.752^{\star \star \star}$ \\
& & $(0.2)$ \\
constant & $0.247^{\star \star \star}$ & 0.06 \\
& $(0.04)$ & $(0.06)$ \\
$\mathrm{R}^{2}$ & & \\
$\mathrm{~N}$ & 0.016 & 0.176 \\
\hline
\end{tabular}

\subsection{What about the Slowest Growing Cities?}

In this subsection I consider the behavior of the $25 \%$ slowest growing cities in each decade country. In the theory developed in Section 3 there is no reason to expect that the rank of the slowest cities exhibits a positive time pattern. This is confirmed in Tables 19 and 21. Once one controls for the number of observations (the second column of each table) the time trend becomes close to zero or negative and it is significant only when we use data on cities. Tables 20 and 22 show the effect of fast urban growth on the growth of 
the rank of the slowest cities. In this case, the coefficient using data on cities turns insignificant and for MAs it is positive but clearly lower than the one reported in Table 8.

Table 19: A Regression of the Average Rank of the 25\% Slowest Growing Cities on Time and Number of Cities

\begin{tabular}{lcc}
\hline & $(\mathbf{1})$ & $(\mathbf{2})$ \\
\hline log time & $0.536^{\star \star \star}$ & $-0.057^{\star}$ \\
& $(0.07)$ & $(0.03)$ \\
log number cities & & $\begin{array}{c}0.904^{\star \star \star} \\
(0.03)\end{array}$ \\
constant & $\begin{array}{c}1.572^{\star \star \star} \\
(0.11)\end{array}$ & $\begin{array}{c}-0.186^{\star \star \star} \\
(0.06)\end{array}$ \\
& & \\
$\mathrm{R}^{2}$ & 0.25 & 0.825 \\
$\mathrm{~N}$ & 536 & 536 \\
\hline
\end{tabular}

Table 20: A Regression of the Growth Rate of the Average Rank of the 25\% Slowest Growing Cities on the Growth Rate of Urban Population and the Growth Rate in the Number of Cities

\begin{tabular}{lcc}
\hline & $(\mathbf{1})$ & $(\mathbf{2})$ \\
\hline growth rate of urban pop & $1.258^{\star \star \star}$ & $\begin{array}{c}-0.304 \\
(0.5)\end{array}$ \\
growth rate of number of cities & & $\begin{array}{c}1.748^{\star \star \star} \\
(0.42)\end{array}$ \\
& & \\
constant & 0.092 & -0.003 \\
& $(0.12)$ & $(0.07)$ \\
$\mathrm{R}^{2}$ & & \\
$\mathrm{~N}$ & 0.069 & 0.696 \\
& 479 & 479 \\
\hline
\end{tabular}


Table 21: A Regression of the Average Rank of the 25\% Slowest Growing MAs on Time and Number of MAs

\begin{tabular}{|c|c|c|}
\hline & (1) & (2) \\
\hline log time & $\begin{array}{c}0.175^{\star \star \star} \\
(0.05)\end{array}$ & $\begin{array}{l}0.012 \\
(0.04)\end{array}$ \\
\hline log number MAs & & $\begin{array}{c}0.661^{* * *} \\
(0.06)\end{array}$ \\
\hline constant & $\begin{array}{c}1.36^{\star \star \star} \\
(0.04)\end{array}$ & $\begin{array}{l}0.193^{\star} \\
(0.11)\end{array}$ \\
\hline $\mathrm{R}^{2}$ & 0.066 & 0.375 \\
\hline $\mathrm{N}$ & 448 & 448 \\
\hline
\end{tabular}

Table 22: A Regression of the Growth Rate of the Average Rank of the 25\% Slowest Growing MAs on the Growth Rate of Urban Population and the Growth Rate in the Number of MAs

\begin{tabular}{lcc}
\hline & $\mathbf{( 1 )}$ & $\mathbf{( 2 )}$ \\
\hline growth rate of urban pop & 0.076 & $0.113^{\star \star}$ \\
& $(0.05)$ & $(0.05)$ \\
growth rate of number of MAs & & $\begin{array}{c}0.349^{\star \star \star} \\
(0.08)\end{array}$ \\
constant & & \\
& $0.189^{\star \star \star}$ & $0.102^{\star \star \star}$ \\
$\mathrm{R}^{2}$ & $(0.02)$ & $(0.03)$ \\
$\mathrm{N}$ & 0.003 & 0.104 \\
\hline
\end{tabular}

\subsection{Using Dummies for Fast Growth of Urban Population}

Finally, as it was mentioned in Section 5.2.3, one can test if the difference in the average growth rate of the rank of the fastest growing cities in periods of rapid and slow urban growth is statistically significant. One way to do this is to run the following regression:

$$
g_{R_{i t}}=\alpha+\beta_{1} D_{F U_{i t}}+\beta_{2} g_{N_{i t}}+u_{i t}
$$

Where as before $g_{R_{i t}}$ and $g_{N_{i t}}$ denote the growth rate of the rank of the fastest growing cities (or MAs) and the growth rate in the number of cities (or MAs) in country $i$ and 
period $t$ respectively. $D_{F U_{i t}}$ is a dummy variable that takes value one in periods of fast urban growth and $u_{i t}$ is a standard error term.

The results of estimating (10) using fixed effects in my sample of cities and MAs are displayed in Tables 23 and 24 respectively. Clearly, the coefficient on the dummy is positive and significant, confirming the previous findings and the high positive correlation detected in the graphs of Appendices B and C.

Table 23: A Regression of the Growth Rate of the Average Rank of the 25\% Fastest Growing Cities on a Dummy for Periods of Fast Urban Growth and the Growth Rate in the Number of Cities

\begin{tabular}{lcc}
\hline & $(\mathbf{1})$ & $(\mathbf{2})$ \\
\hline dummy fast urban growth & $1.008^{\star \star \star}$ & $0.299^{\star \star}$ \\
& $(0.15)$ & $(0.12)$ \\
growth rate of number of cities & & $\begin{array}{c}0.864^{\star \star \star} \\
(0.05)\end{array}$ \\
constant & & \\
& $0.118^{\star \star}$ & 0.048 \\
$\mathrm{R}^{2}$ & $(0.06)$ & $(0.05)$ \\
$\mathrm{N}$ & 0.126 & 0.596 \\
\hline
\end{tabular}

Table 24: A Regression of the Growth Rate of the Average Rank of the 25\% Fastest Growing MAs on a Dummy for Periods of Fast Urban Growth and the Growth Rate in the Number of MAs

\begin{tabular}{lcc}
\hline & $\mathbf{( 1 )}$ & $\mathbf{( 2 )}$ \\
\hline dummy fast urban growth & $0.253^{\star}$ & $0.273^{\star \star}$ \\
& $(0.14)$ & $(0.12)$ \\
growth rate of number of MAs & & $\begin{array}{c}0.716^{\star \star \star} \\
(0.2)\end{array}$ \\
constant & & \\
& $0.229^{\star \star \star}$ & 0.077 \\
$\mathrm{R}^{2}$ & $(0.05)$ & $(0.06)$ \\
$\mathrm{N}$ & 0.017 & 0.199 \\
\hline
\end{tabular}


Comparing these estimates with those in tables 6 and 7 it is clear that the results are qualitatively very similar. Periods of fast growth in urban population are associated with rapid increases in the rank of the fastest growing cities.

\section{Conclusions}

In this paper I study the evolution of city sizes in different countries over very long periods of time using data on administratively defined cities and metropolitan areas. I document three novel empirical facts. The first one is that the cross section of cities growth rates is clearly skewed to the right in most countries and decades. This indicates that at each decade a few cities grow much faster than the rest. Second, the rank of these fast growing cities increases as time goes by- the initially largest city is the first one to grow, then the second one, then the third one, and so on.

Finally, it is shown that sequential city growth is most relevant in periods of rapid growth in urban population. This last finding is consistent with the hypothesis that Gibrat's law is an approximate good description of the growth process of cities in countries that are not subject to rapid urbanization but not so much for rapidly urbanizing countries. These results are robust to the cutoff that determines the sample selection, the definition of what constitutes a "fast-growing" city and a period of "rapid growth in urban population" and to the regression technique employed.

From a theoretical point of view these three novel empirical results are entirely consistent with a simple urban model with increasing returns and congestion costs that predicts that cities form and grow sequentially. In the model, a small initial advantage of one city in terms of installed capital generates periods in which this city is the fastest to grow. Eventually, congestion costs associated with the stock of capital become large enough for the second largest city to start its period of solo growth. 


\section{References}

Beeson, P. E., and D. N. DeJong (2002), “Divergence.” Contributions to Macroeconomics, vol. 2, issue 1, pp. 1049-???

Beeson P. E., DeJong D. N., and W. Troesken (2001), "Population Growth in U.S. Counties, 1840-1990.” Regional Science and Urban Economics, Volume 31, Number 6, November, pp. 669-99

Black, D., Henderson, J. V. (2003), "Urban evolution in the USA.” Journal of Economic Geography 3, pp. 343-73

Brinkhoff, T. City Population, http://www.citypopulation.de

Chatterjee, S. and G. A. Carlino (2001), "Aggregate Metropolitan Employment Growth and the Deconcentration of Metropolitan Employment." Journal of Monetary Economics, 48, pp. 549-83

Cuberes, D. (2009), "A Model of Sequential City Growth." forthcoming, Contributions, B.E. Journal of Macroeconomics

Davis, J. C., and J. V. Henderson (2003), "Evidence on the Political Economy of the Urbanization Process.” Journal of Urban Economics 53, pp. 98-125

Davis, D. R., and D. E. Weinstein (2002), "Bones, Bombs, and Break Points: the Geography of Economic Activity.” American Economic Review 92, pp. 1269-89

D'Agostino, R. B., A. Balanger, and R. B. D'Agostino, Jr. (1990), “A Suggestion for Using Powerful and Informative Tests of Normality." The American Statistician 44(4), pp. 316-21

Eaton, J., and Z. Eckstein (1997), "Cities and Growth: Theory and Evidence from France and Japan.” Regional Science and Urban Economics, XXVII, pp. 443-74

Eeckhout, J. (2004), “Gibrat’s Law for (All) Cities.” American Economic Review, vol. 94(5), pp. 1429-51, December

Eeckhout, J. (2008), "Gibrat's Law for (All) Cities: Reply." forthcoming, American Economic Review

Ehrlich, S., and J. Gyourko (2000), "Changes in the Scale and Size Distribution of U.S Metropolitan Areas during the Twentieth Century.” Urban Studies, Vol. 37, No. 7, pp. 1063-77 
Gabaix, X., and Y. Ioannides (2004), "Evolution of City Size Distributions.” in J. Vernon Henderson and Jacques-Francois Thisse, eds., Handbook of Regional and Urban Economics IV: Cities and Geography, Chapter 53, pp. 2341-78, North-Holland

Gibrat, R. (1931), Les inégalités economiques. Paris, France: Librairie du Recueil Sirey

Glaeser, E., and J. Gyourko (2005), “Urban Decline and Durable Housing.” Journal of Political Economy, vol. 113:22, pp. 345-75

Glaeser, E., J. Scheinkman, and A. Shleifer (1995), "Economic Growth in a CrossSection of Cities.” Journal of Monetary Economics 36, pp. 117-43

González-Val, R. (2007), "The Evolution of the U.S. Urban Structure from a Long-Run Perspective (1900-2000).” working paper

Henderson, J. V., http://www.econ.brown.edu/faculty/henderson/worldcities.html

Henderson, J. V., and A. J. Venables (2009), "Dynamics of City Formation.” Review of Economic Dynamics, vol. 12(2), April, pp. 233-54.

Henderson, J. V., and H. G. Wang (2007), "Urbanization and City Growth: The Role of Institutions.” Regional Science and Urban Economics, vol. 37(3), pp. 283-313, May

Ioannides, Y. M., and H. G. Overman (2003), “Zipf’s Law for Cities: An Empirical Examination.” Regional Science and Urban Economics 33, pp. 127-37

Kim, S. (2007), "Changes in the Nature of Urban Spatial Structure in the United States, 1890-2000.” Journal of Regional Science, Vol. 47, No. 2, pp. 273-87

Lahmeyer, J., http://www.library.uu.nl/wesp/jalahome.htm

Romer, P. M. (1986), “Increasing Returns and Long-Run Growth.” Journal of Political Economy 94, 5, October, pp. 1002-37

Royston, P. (1991), “Comment on sg3.4 and an Improved D'Agostino Test.” Stata Technical Bulletin 3:23-24. Reprinted in Stata Technical Bulletin Reprints, vol. 1, pp. 110-12 


\section{APPENDICES}

See second paper file at:

http://cep.lse.ac.uk/seminarpapers/23-10-09-

CUBappendices.pdf 